IZA DP No. 9673

Sleep Restriction and Time-of-Day Impacts on Simple Social Interaction

David L. Dickinson

Todd McElroy

January 2016 


\title{
Sleep Restriction and Time-of-Day Impacts on Simple Social Interaction
}

\author{
David L. Dickinson \\ CERPA, Appalachian State University, \\ IZA and ESI \\ Todd McElroy \\ Florida Gulf Coast University
}
Discussion Paper No. 9673
January 2016

\author{
IZA \\ P.O. Box 7240 \\ 53072 Bonn \\ Germany \\ Phone: +49-228-3894-0 \\ Fax: +49-228-3894-180 \\ E-mail: iza@iza.org
}

Any opinions expressed here are those of the author(s) and not those of IZA. Research published in this series may include views on policy, but the institute itself takes no institutional policy positions. The IZA research network is committed to the IZA Guiding Principles of Research Integrity.

The Institute for the Study of Labor (IZA) in Bonn is a local and virtual international research center and a place of communication between science, politics and business. IZA is an independent nonprofit organization supported by Deutsche Post Foundation. The center is associated with the University of Bonn and offers a stimulating research environment through its international network, workshops and conferences, data service, project support, research visits and doctoral program. IZA engages in (i) original and internationally competitive research in all fields of labor economics, (ii) development of policy concepts, and (iii) dissemination of research results and concepts to the interested public.

IZA Discussion Papers often represent preliminary work and are circulated to encourage discussion. Citation of such a paper should account for its provisional character. A revised version may be available directly from the author. 


\title{
ABSTRACT \\ Sleep Restriction and Time-of-Day Impacts on Simple Social Interaction
}

\section{Moderate sleep restriction increases greed, reduces trust and trustworthiness}

\begin{abstract}
Simple bargaining games are the foundation of more complex social interactions necessary for healthy relationships and well-functioning societies. Neuroscience research has shown that high-level deliberative thinking processes are necessary for social-decision making - it seems cognitively less demanding to be greedy or to mistrust. In this paper, our focus is on how commonly-experienced adverse sleep states, which are known to harm deliberative thinking, impact outcomes in the classic simple bargaining games (ultimatum, dictator, and trust games). Specifically, we experimentally manipulate sleep states of 184 young-adult subjects who took part in a 3 week experimental protocol. Subjects were administered each game twice: once after a full week of sleep restriction and once after a full week of well-rested sleep levels. Subjects were also randomly assigned to early morning (7:30 am) or later evening $(10: 00 \mathrm{pm})$ sessions to manipulate the optimality of the time-of-day of the decisions. We find a robust result of increased greed, reduced trust, and reduced trustworthiness following sleep restriction, after controlling for demographics and session indicators. We find no significant direct impact of circadian timing on decisions for these tasks. However, the mediating variable for these sleep manipulation effects is subjective sleepiness, and both sleep restriction and suboptimal circadian timing significantly increase self-reported sleepiness. These results are consistent with the hypothesis that increased sleepiness reduces the relative input of deliberate thinking in social interactions.
\end{abstract}

JEL Classification: $\quad$ C7, C9

Keywords: $\quad$ sleep, time-of-day, ultimatum, dictator, trust, bargaining

Corresponding author:

David L. Dickinson

Department of Economics

Appalachian State University

Boone, NC 28608

USA

E-mail: dickinsondl@appstate.edu 
Prosocial preferences help encourage positive interactions and promote economic institutions that require trust/trustworthiness. We explore how commonly experienced levels of sleep restriction and the time-of-day of decision making may impact well-established outcomes in ultimatum, dictator, and trust games. The literature is virtually silent on the impact of sleep loss or sleepiness social decision making, and the rare exceptions examine these questions using total sleep loss protocols $(1,2)$. A main contribution of our work is to experimentally manipulate sleep in ecologically valid ways that are highly applicable to real world decision makers. In this way we add to our understanding of the likely impact of commonly experienced adverse sleep states on social decision outcomes. Our hypotheses are derived from a dualprocess framework where automatic thinking (System 1) and deliberate thinking (System 2) processes contribute to varying degrees towards decision outcomes. A more sleepy state is hypothesized to increase the relative input of System 1 in a decision. Assuming self-interest and mistrust increase as the relative input of System 1 increases, such as when System 2 regions implicated in social decision making are compromised (1-5), we hypothesize that sleepiness will adversely impact prosocial behavior. The implications are significant given current societal trends towards reduced sleep and suboptimal time-of-day scheduling, and these results identify a key determinant of inefficiencies in certain social exchanges.

Critical to our hypotheses is the argument that prosocial behavior requires deliberate thinking and active suppression of the more automatic response to be myopically selfinterested $(3,6)$. Some recent evidence challenges the notion that greed is the automatic or intuitive response in cooperative environments (7). However, the larger body of literature (810), as well as more recent neural evidence, points to a connection between prosocial decisions and activation of brain regions known to be important for deliberative thinking $(3,4,6)$. Existing research on the effects of sleep deprivation and off-peak time-of-day (or "circadian mismatched") on decision making also informed our hypotheses. To our knowledge, the extant literature is consistent with the hypotheses that decisions are relatively more influenced by System 1 processes when sleep deprived or circadian mismatched (5,11-14).

To examine our research question, we recruited 184 young adult subjects ( 30 control: 154 treatment: $18-39$ years old, mean $21.66 \pm 4.43$ years old) to participate in a 3 week study. 
Based on a pre-screen survey, treatment subjects recruited were validated morning-type or evening-type diurnal preference young adults (15) who were then randomly assigned to participate in two early morning (7:30am-9:00am) or late evening (10:00pm-11:30pm) decision sessions (Table S1). Control subjects were validated intermediate-type who participated in sessions between 10:00am and 3:00pm. Subjects were given sleep diaries and wrist-worn clinical actigraphy devices to objectively monitor sleep levels over the course of the 3 weeks. Treatment subjects were prescribed a sleep schedule that included one week of 5-6 hrs/night attempting to sleep (sleep restricted=SR) and one week of 8-9 hrs/night attempting to sleep (well-rested=WR). Control subjects were prescribed two weeks of well-rested sleep levels. For all subjects, week 2 of the protocol was an ad lib sleep week used to wash out the effects of the week \#1 condition prior to starting the week \#3 condition. Upon completion of the study scoring of the sleep data, 149 (30 control: 119 treatment) subjects had complete data and were deemed compliant. Compliant treatment subjects slept approximately 1.5 hours more per evening during the SR week than during the WR week (see Fig. S1 and other Supp. Mat. for details on compliance scoring).

At the end of the SR and WR weeks (counterbalanced in order across subjects), subjects participated in a decision session that included administration of the classic ultimatum, dictator, and trust games (see Supp. Mat., Methods and Materials). The ultimatum game allows the responder the option to reject a proposal, which case both parties receive $\$ 0$, whereas the dictator game allows the dictator to decide the pie split without the possibility of rejection. Hence, ultimatum proposals involve a conflict between greed and risk aversion given that greedier initial offers are more likely to be rejected. In the trust game, the amount the first mover passes along, or "trusts" to the second mover is tripled by the experimenters and the second mover then decides how much, if any, to pass back.

As a manipulation check, subjects are asked to self-report sleepiness during the decision sessions using the Karolinska Sleepiness scale $(16,17)$. We test for manipulation effects using a random effects estimation of self-report sleepiness on treatment manipulations and other demographic and sleep control variables. Both the sleep restriction and circadian mismatch manipulations are estimated to significantly increase sleepiness $(p<.01)$-the magnitude of the 
circadian mismatch effect is roughly equivalent to the estimated effect of one less hour of sleep per night during the preceding week (Table S3). On a subset of our data $(n=80)$, we also administered an affective states instrument and document increased irritability, and reduced attentiveness and alertness due to sleep restriction (Figure S2). There is the likelihood of domain-specific nonlinear interaction effects between sleep levels and circadian misalignment $(18,19)$. We nevertheless exclude such an interaction term from our analysis given the lack of ex ante hypothesis as to its form or how it might vary across decision tasks we administer.

Figs. 1-4 plot the predicted level of the key dependent variable from each game as a function of the a subject's Personal Sleep Deprivation Level (or "Personal SD"), which is the difference between a subject's self-reported optimal nightly sleep and the objectively measured nightly sleep over the prior week. All Figures hold demographics, session descriptors, and other sleep related control variables constant (see Tables S5-S8). Random effects estimations account for the two observations per subject. Except for the case of ultimatum game outcomes in Fig. 1, key results are robust to alternative specifications and alternative coding options of the key sleep level variable (see Tables S4-S8). Also, we note that the estimated effect of circadian mismatch on bargaining outcomes is insignificant in each case, and so Figs 1-4 show only the outcome measure prediction as a function of sleep restriction.

Figs 1 and 2 show the estimated increased greed by first movers in both the ultimatum and dictator games as a result of sleep restriction. The ultimatum result is less robust and a smaller effect size (see Tables S4, S5), which is perhaps not surprising given that first-mover greed in the ultimatum game conflicts with the desire to avoid rejection. A null result not shown in the Figures is that second-mover ultimatum decisions-minimum acceptable offersare not significantly affected by sleep restriction (Tables S4, S5). As with first-mover ultimatum decisions, second-mover minimum acceptable offers must balance the conflict of greed and the potential of a zero payoff if an offer is rejected. The dictator result is therefore a more clear picture of the impact of sleep restriction on unconstrained greed (or altruism).

Figs. 3 and 4 show predicted lower levels of trust and trustworthiness as a result of sleep restriction. Fig. 3 also shows the estimated null impact on trust decisions when a "risk" version of the trust game was played. In this version of the trust game, it is common 
knowledge that the $2^{\text {nd }}$-mover is an automated pass-back algorithm as opposed to another subject in the experiment group. This "non-human" trust game disentangles the importance of risk embedded in a social interaction from pure risk. As seen in Fig. 3, sleep restriction is predicted to only impact first-mover choices in the actual 2-person simple exchange of the trust game. The trust result is quite robust (see Tables S7, S9) and highlights an inefficiency that results from mild but chronic sleep restriction. Namely, lower levels of trust imply unrealized gains in simple social interactions.

Trustworthiness is also negatively impacted by sleep restriction, as shown in Fig. 4 . To further examine trustworthiness when a significant initial trust signal is sent, we coded an alternative dependent variable as the average pass-back amount chosen when more than half the pie is initially trusted. With this alternative coding of the dependent variable "trustworthiness", the negative coefficient on Personal SD is even larger in magnitude and more highly statistically significant than what is shown in Fig. 4 (Table S8, see also note below Table S4). This indicates that sleep restriction may have a particularly damaging effect on future interactions when more significant and clear trust signals are sent. Given the sleep restriction effect on trustworthiness, one might argue that reduced trust results from an accurate anticipation of reduced trustworthiness. While we do not directly test whether this is the case, we reject this interpretation of the trust game results for two reasons: First, similar reasoning cannot not explain why sleepy ultimatum proposers keep more money but yet the second-movers' MAOs do not change. Secondly, this interpretation implies that sleepy subjects retain anticipation skills requiring theory-of-mind brain region activation, which is a region harmed by sleep loss $(20,21)$.

Because our sleep and circadian manipulations are intended to alter sleepiness, we also evaluated whether sleepiness mediates these results (Table S9). The proposed mediating variable is endogenous, which requires estimation by 2 SLS variables approach. In step one, we regressed the Karolinska sleepiness scores on demographics and sleep variables. As noted earlier, both sleep restriction and circadian mismatch are statistically significant $(p<.01)$ predictors of higher sleepiness scores. This first stage estimation identifies the extent that variation in sleepiness is due to subject-specific and experimental manipulations in our design. 
Note that the impact of gender is implicit in these results, as we find that female subjects are significantly sleepier, controlling for other demographics and sleep variables.

Step two used the predicted values of sleepiness scores as a covariate (instrument) in the bargaining models. In each instance, the instrument for sleepiness significantly predicts the same key outcomes that were impacted by sleep restriction in our initial analysis. That is, the instrument for sleepiness predicts higher Ultimatum proposal and Dictator greed, lower trust, and lower trustworthiness (see Table S9). These results indicate that our experimental conditions alter behavior via their impact on subjective sleepiness. They also highlight that, while circadian mismatch is not estimated to directly impact behavioral outcomes in these games, circadian mismatch does indirectly affect decisions via its impact on sleepiness.

Here we have examined the impact of chronic but relatively mild sleep restriction and suboptimal circadian timing on decisions in simple bargaining games. These games form the building blocks of many more complex interactive decision environments where social preferences loom large. Because we examined subjects in an ecologically valid setting, where they were free to engage in typical compensatory strategies to combat the sleepiness caused by our experimental manipulation, our results can be viewed as a conservative estimate of the likely impact of common sleep states on bargaining outcomes. We report a robust result where increased sleepiness (impacted most significantly by sleep restriction) increases greed, reduces trust, and reduces trustworthiness. At least for short-term social interactions, our results imply that common sleep states reduce pro-social outcomes and lead to unrealized gains (i.e., inefficiencies) in simple exchanges that require trust. Future research should seek to evaluate whether these effects are also robust to repeated or longer-term interactions between individuals. 
Figure 1: Forecast derived from Table S5 (Supp. Info), for Session 2 level (i.e., Session\#3 Dummy=0). Levels of all variables estimated as statistically insignificant set to zero. Figure shown over range of value of Personal SD observed in sample of compliant treatment subjects. Results show that when ultimatum proposers are more chronically (partially) sleep restricted, they demand more (offer less) of the $\$ 10$ pie. Note: ultimatum second movers were not estimated to change their minimum acceptable offers due to sleep restriction.

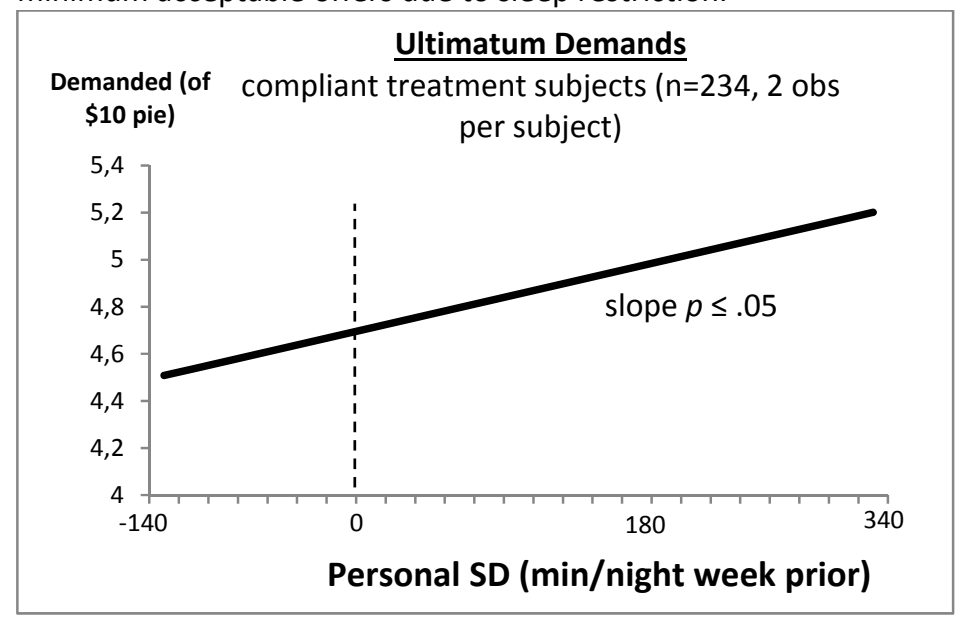

Figure 2: Forecast derived from Table S6 (Supp. Info), for Session 2 level (i.e., Session\#3 Dummy=0). Levels of all variables estimated as statistically insignificant set to zero. Figure shown over range of value of Personal SD observed in sample of compliant treatment subjects. Results show that when dictators are more chronically (partially) sleep restricted, they demand more (offer less) of the $\$ 10$ pie.

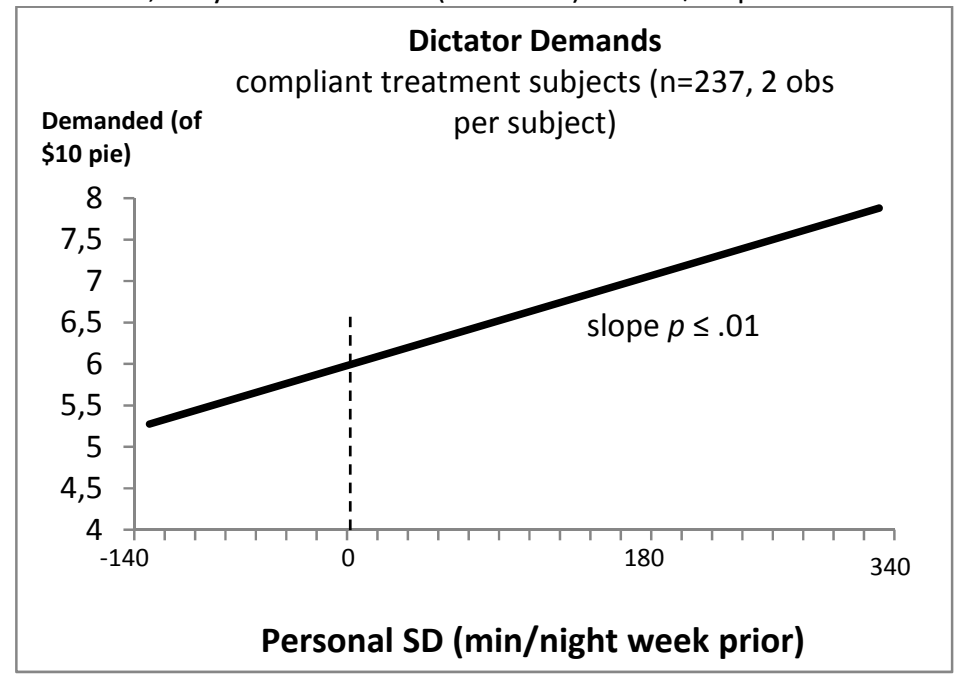


Figure 3: Forecast derived from Table S7 (Supp. Info), for Session 2 level (i.e., Session\#3 Dummy=0). Levels of all variables estimated as statistically insignificant set to zero. Figure shown over range of value of Personal SD observed in sample of compliant treatment subjects. Results show that when subjects are more chronically (partially) sleep restricted, they trust less of the \$10 pie. Non-human trust line shows the predicted level of trust (i.e., amount sent to $2^{\text {nd }}$-mover) when $2^{\text {nd }}$-mover is known to be an automatic pass-back algorithm as opposed to another subject in the experiment group. Trusted amounts in that version of the game are not significantly affected by Personal SD.

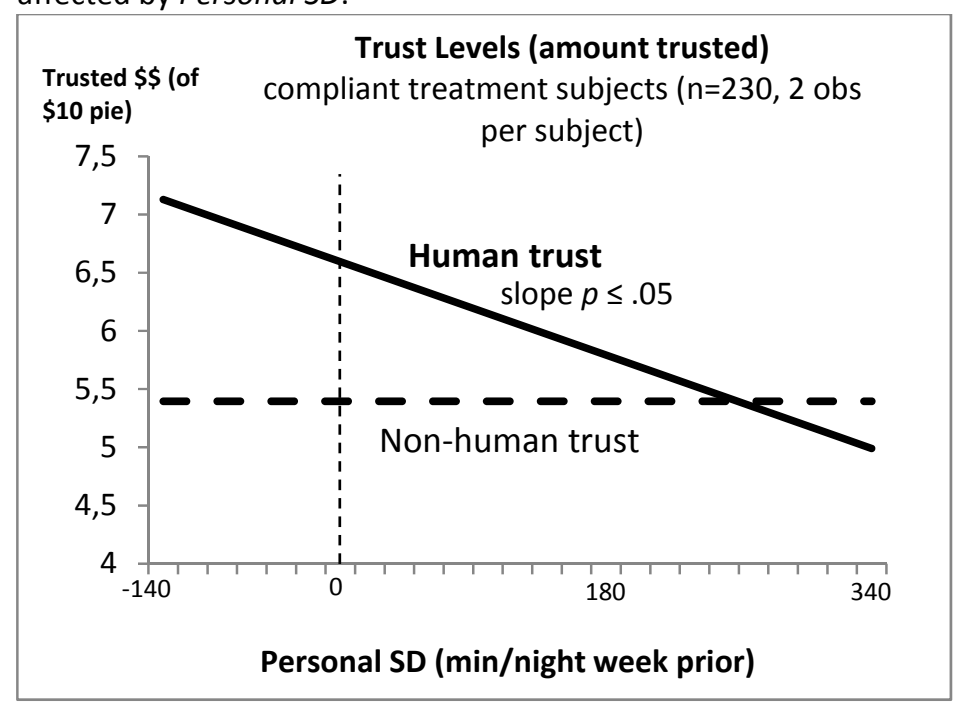

Figure 4: Forecast derived from Table S8, column 2 (Supp. Info) for Session 2 level (i.e., Session\#3 Dummy=0). Levels of all variables estimated as statistically insignificant set to zero. Figure shown over range of value of Personal SD observed in sample of compliant treatment subjects. Results show that when subjects are more chronically (partially) sleep restricted, they return an average \% of the pie that is lower (across all potential amounts the $1^{\text {st }}$-mover may trust to the $2^{\text {nd }}$-mover.

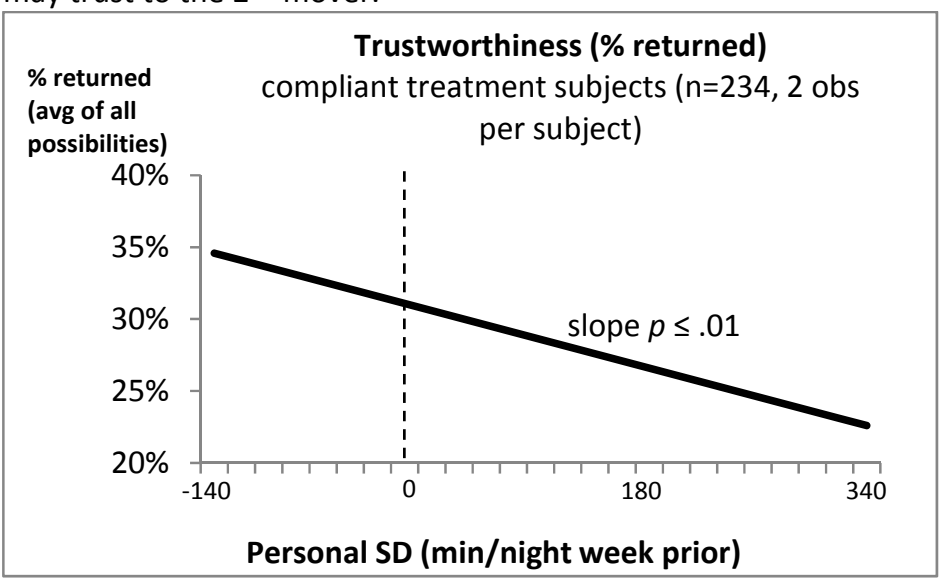




\section{REFERENCES}

1. Anderson, C. \& Dickinson, D. L. Bargaining and Trust: The Effects of $36 \mathrm{hr}$ Sleep Deprivation on Socially Interactive Decisions. Journal of Sleep Research, 19, 54-63 (2010).

2. Ferrara, M., Bottasso, A., Tempesta, D., Carrieri, M., De Gennaro, L., \& Ponti, G. 2015. Gender differences in sleep deprivation effects on risk and inequality aversion: Evidence from an economic experiment. PLOS ONE, 10(3), e0120029.

3. Rilling, J. K. \& Sanfey, A. G. The neuroscience of social decision-making. Annu. Rev. Psychol 62, 23-48 (2011).

4. Krajbich, I., Adolphs, R., Tranel, D., Denburg, N. L., \& Camerer, C. F. Economic games quantify diminished sense of guilt in patients with damage to the prefrontal cortex. J. Neurosci 29, 2188-2192 (2009).

5. Chee, M. W., \& Chuah, L. Y. Functional neuroimaging insights into how sleep and sleep deprivation affect memory and cognition. Curr. Opin. Neurol. 21, 417-423 (2008).

6. Fehr, E. \& Camerer, C. Social neuroeconomics: the neural circuitry of social preferences. Trends in Cogn Sci 11(10), 419-427 (2007).

7. Rand, D. G., Greene, J. D., \& Nowak, M. A. Spontaneous giving and calculated greed. Nature 489, 427-430 (2012).

8. Verkoeijen, P. P. J. L. \& Bouwmeester, S. Does intuition cause cooperation? PLOS ONE 9(5), e96654 (2014).

9. Tinghög, G., Andersson, D., Bonn, C, Böttiger, H, Josephson, C. et al. Intuition and cooperation reconsidered. Nature 498, E1-E2 (2013).

10. Krajbich, I., Björn, B., Hare, T. \& Fehr, E. Rethinking fast and slow based on a critique of reaction-time reverse inference. Nat Commun 6, 7455 (2015).

11. Horn, J. A. Human sleep, sleep loss and behavior. Implications for the prefrontal cortex and psychiatric behavior. Br. J. Psychiatry 162, 413-419 (1993).

12. Yoo, S.-S., Guhar, N., Hu, P., Jolesz, F. A., \& Wlaker, M. P. The human emotional brain without sleep-a prefrontal amygdale disconnect. Curr. Biol. 17, 877-878 (2007).

13. McElroy, T. \& Dickinson, D. L. Thoughtful days and valenced nights: How much will you think about the problem? Judgment and Decision Making, 5(7), 516-523 (2010).

14. Dickinson, D. L, \& McElroy, T. Rationality Around the Clock: Sleep and Time-of-Day Effects on Guessing Game Responses. Economics Letters, 108(2), 245-248 (2010).

15. Adan A, Almiral H (1991) Horne and Ostberg morningness-eveningness questionnaire: A reduced scale. Pers Individ Dif 12(3): 241-253.

16. Åkerstedt, T. \& Gillberg, M. Subjective and objective sleepiness in the active individual. Int J Neurosci, 52(1-2), 29-37 (1990).

17. Kaida K., Takahashi, M., Åkerstedt, .T, Nakata, A., Otsuka, Y. , Haratani, T. \& Fukasawa, K. Validation of the Karolinska sleepiness scale against performance and EEG variables. Clinical Neurophysiology, 117, 1574-1581 (2006).

18. Van Dongen, H. P. A. \& Dinges, D. F. Investigating the interaction between the homeostatic and circadian processes of sleep-wake regulation for the prediction of waking neurobehavioural performance. Journal of Sleep Research, 12, 181-187 (2003). 
19. Burke, T. M., Scheer, F. A. J. L., Ronda, J. M., Czeisler, C. A. \& Wright, K. P. Sleep inertia, sleep homeostatic and circadian influences on higher-order cognitive functions. Journal of Sleep Research, 24, 364-371 (2015).

20. Coricelli, G., \& Nagel, R. Neural correlates of depth of strategic reasoning in medial prefrontal cortex. Proceeding of the National Academy of Sciences, 106, 9163-9168 (2009).

21. Dickinson, D. L., \& McElroy, T. Circadian effects on strategic reasoning. Experimental Economics, 15(3), 444-459 (2012). 


\section{SUPPLEMENTARY MATERIALS}

1. Methods and Materials

2. Sample Information

3. Statistical Analysis

\section{METHODS AND MATERIALS}

\section{Sleep Data Acquisition}

Actigraphy data acquisition (Actiwatch Spectrum Plus devices; Philips Respironics) was at 30-second time epochs. Each epoch is initially scored as "sleep" or "wake" with manufacturer's software. Rest period start/end times are then adjusted manually, if necessary, using subject-entered actigraph event markers and with the input of complementary sleep diaries. All manual scoring is conducted using validated scoring protocols (22).

The devices use an MEMS type accelerometer and sample data at $32 \mathrm{~Hz}$. Devices are waterproof at $1 \mathrm{~m}$ for 30 minutes and so subjects were instructed to wear them $24 \mathrm{hr}$ a day during the 3-week protocol, except for the exceptional removal to avoid device damage (e.g., contact sports, working with chemicals, etc). Battery life at 30-second data sampling epochs is over 30 days and so subjects had no concerns with battery life or device recharge.

\section{Circadian Match/Mismatch Protocol: Details}

We first administered a large-scale online survey meant to provide information on subject sleep habits. Over several waves of the online survey we generated several thousand responses to our survey (mostly student responses). The first page of the survey was a consent page requiring consent to continue. In addition to asking for basic demographic information, the survey administered a set of validated screener questions for anxiety and depression. Subjects at risk of major depressive or anxiety disorder were not recruited for our study, given the correlation between these conditions and sleep disturbance. Importantly, within the online survey we also included a validated measure of their diurnal preference, which is assessed in the survey using the short form of the morningness-eveningness questionnaire, henceforth rMEQ (15). The rMEQ classifies individuals on a scale of 4-25, with morning-types having rMEQ score from 18-25 and evening-types having rMEQ score from 4-11. While this diurnal preference measure is based on self-reports of the subjects, it has been validated against physiological data on oral temperatures (23) and is a standard tool in circadian research.

From our database, we recruit morning-types and evening-types, who we had randomly assigned, ex ante, to participate in either a morning (7:30 a.m.) or an evening (10:00 p.m.) experiment session. This resulted in approximately half of our sample being circadian matched (mismatched) for the risky choice experiment. ${ }^{1}$ Table S1 shows how the circadian manipulation distributed subjects across our experimental design cells.

\footnotetext{
${ }^{1}$ Due to the rarity of true morning-type subjects-less than $10 \%$ in young adult populations are morning-types (24)-we extend our rMEQ cutoff to include rMEQ scores of 16 and 17. To compensate, we only recruit the more extreme (and still abundant) evening-type subjects with rMEQ scores from 4-9. In this way, our sample is still drawn from the tails of the $\mathrm{rMEQ}$ distribution and eliminates the same amount of support from the non-tail portion of the $r M E Q$ distribution compared to if we had used the traditional morning-type cutoff ( $r M E Q=18)$ but included non-extreme evening types (rMEQ=10-11) in our sample.
} 


\section{Simple Bargaining: Ultimatum, Trust, Dictator games}

We administer the classic versions of these games using a $\$ 10$ starting sum. Note that for the Trust game we do not endow the responder with any money (and so, a subject attempting to equalize firstmover/second-mover earnings will send back a different amount than if the same endowed both first and second-mover with $\$ 10)$.

The games are administered via the strategy method whereby all subjects made decisions in the role of both first-mover and second-mover prior to knowing to which role he/she was randomly assigned. Only after all decisions were made do we make random role assignments (first- or second-mover), randomly assign subjects to an anonymous counterpart in the same session, and then randomly select one of the games to count for payoff during that decision session. Outcomes in this game were only revealed at the end of the decision session, when payoff for these and other decision tasks were given out in cash.

Table S1

Sample Size Per Design Cell (treatment subjects)

Morning Session

\begin{tabular}{c|c|c|}
\cline { 2 - 3 } Morning-type & $34(30)$ & $38(28)$ \\
\cline { 2 - 3 } Evening-type & $39(30)$ & $38(31)$ \\
\cline { 2 - 3 } & $\begin{array}{r}\text { Sample size = 149 subjects } \\
\text { Matched obs }=76, \text { Mismatched obs }=73 \\
\text { (compliant \& sleep data intact shown in parenthesis) }\end{array}$ \\
\hline
\end{tabular}

Note: Circadian mismatches cells shaded 


\section{SAMPLE INFORMATION}

\section{Attrition and Sample Selection}

Recruited subjects in this study are categorizes as either completing the study, or failing to complete the study. Among those failing to complete the study, some dropped out at some point during the 3 week protocol, while others had signed up but failed to show up for Session \#1. Below, we show results of estimating the likelihood of completing the study among recruited subjects as a function of demographics and sleep-related controls. Note that, though Anxiety and Depression screener scores are included as covariates, subjects that scored above standard cutoffs for significant risk of major depressive or anxiety disorder were not recruited for the study. The only covariates that predict finishing the study are Depression and Anxiety, and so we include these in our main outcomes models to remove any effect of these variables, via selection into the final sample, on task outcome variables.

Table S2: Determinants of Protocol Completion

Random effects Probit estimations: Dependent Variable $=\operatorname{FINISHED~}(0,1)$ )

\begin{tabular}{|c|c|c|}
\hline Variable & $\begin{array}{c}\text { Model 1 } \\
\text { All Recruited Treatment } \\
\text { Subjects (n=220) }\end{array}$ & $\begin{array}{c}\text { Conditioned on Subjects Showing } \\
\text { up Day 1 ( } \mathbf{n = 1 8 8 )}\end{array}$ \\
\hline Constant & $1.130(.980)$ & $.900(1.12)$ \\
\hline SD Week First (=1) & $-.162(.183)$ & $-.065(.222)$ \\
\hline Age & $-.021(.025)$ & $-.032(.028)$ \\
\hline Female (=1) & $.038(.186)$ & $-.174(.235)$ \\
\hline Optimal Sleep level (self-report) & $-.055(.092)$ & $.049(.108)$ \\
\hline Depression & $-.206(.121)^{*}$ & $-.271(.149)^{*}$ \\
\hline Anxiety & $.053(.041)$ & $.128(.051)^{* *}$ \\
\hline Epworth Sleepiness & $.010(.028)$ & $-.009(.033)$ \\
\hline Nonstudent subject (=1) & $.099(.431)$ & $.236(.518)$ \\
\hline MEQ score & $.018(.018)$ & $.014(.022)$ \\
\hline Minority Subject (=1) & $-.131(.359)$ & $-.054(.450)$ \\
\hline LR chi-squared test of model & 6.67 & 9.35 \\
\hline
\end{tabular}

Notes: All recruited Control Subjects showed up and finished the protocol and are not included in the above estimations.

\section{Determination of Subject Compliance}

While subjects were asked to comply with a 5-6 hr/night (SR) and 8-9 hr/night (WR) schedule during the treatment weeks, attempted sleep does not necessarily translate into actual objectively verified sleep. Figure S1 below shows the distribution of average within-subject difference in nightly sleep between the SR and WR weeks (as determined by actigraphy data and validated scoring protocol using complementary sleep diaries) for control versus treatment subjects). The SR and WR weeks were counterbalanced in order across subject groups. All 145 treatment subjects for which we have complete actigraphy data are included in the treatment subjects distribution in Fig. S1. As expected, control subjects who were asked to comply with a WR schedule both week \#1 and week \#3 of the protocol show 
no statistically difference in average nightly sleep between weeks \#1 and \#3. Treatment subjects slept approximately an hour and a half less each night of the week prior to decision making, though there is heterogeneity across subjects as to the degree or compliance (i.e., the within-subject sleep difference). Importantly, Fig. S1 shows that our chosen cutoff for compliance of WR-SR sleep difference of at least 60 minutes per night is adequate to be confident that such subjects were not behaving as control subjects (see overlap point of distributions). Fig. S1 also highlights the importance of including the richness of the nightly sleep the week prior to decision making as an independent variable in our analysis, as opposed to merely coding a categorical $0 / 1$ variable for indicating the sleep restriction week (although we do such analysis as well in confirming the robustness of our results).

Figure S1: Sleep difference distributions (control vs. treatment subjects)

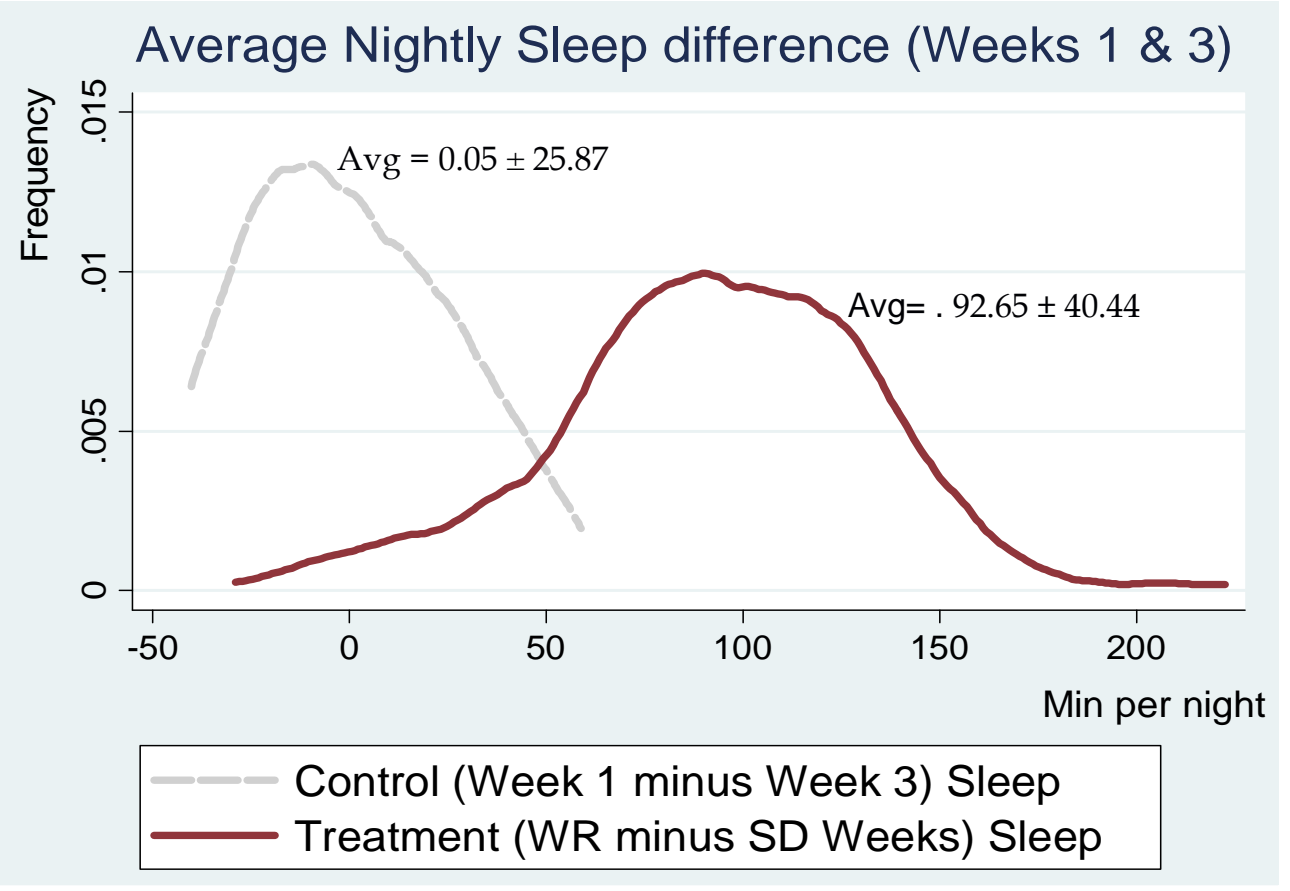




\section{Sleepiness (self-report) manipulation check-conditional analysis}

Simple unconditional means tests show an increase in self-reported sleepiness for the sleep-restricted week compared to the well-rested week ( $z=4.196, p<.01$ : signed rank tests). A similar test finds an insignificant impact on self-reported sleepiness due to the circadian mismatch manipulation ( $p>.10)$. However, such tests do not account for repeat observations per subjects and other variables' impact on sleepiness. The table below shows the impact of sleep restriction (i.e., Personal SD), circadian mismatch, and other subject-specific and session control variables on the average Karolinska sleepiness score for a given subject during a given session (pre- and post-task Karolinska scores are averaged into one score).

Table S3: Determinants of Sleepiness

Random effects GLS regression (for full compliant treatment sample, $n=119$ subjects, 236 obs) Dependent Variable $=$ Self Report Karolinska Sleepiness Score (1-9)

\begin{tabular}{|c|c|c|}
\hline Variable & Model 1 & Model 2 \\
\hline Constant & $4.1061(.3997)^{* * *}$ & $2.6714(.7246)^{* * *}$ \\
\hline Age & --- & $.0473(.0264)^{*}$ \\
\hline Female (=1) & --- & $.8689(.2305)^{* * *}$ \\
\hline Session3 (=1) & $-.383(.2240)^{*}$ & $-.3776(.2168)^{*}$ \\
\hline Depression & --- & $-.2795(.1518)^{*}$ \\
\hline Anxiety & --- & $-.00418(.0508)$ \\
\hline Personal SD & $.0103(.0014)^{* * *}$ & $.0105(.0014)^{* * *}$ \\
\hline Morning Session (=1) & $-.6182(.2268)^{* * *}$ & $-.6573(.2221)^{* * *}$ \\
\hline MEQ score & $.0426(.0210)^{* *}$ & $.00887(.0219)$ \\
\hline Circadian Mismatched (=1) & $.6830(.2289)^{* * *}$ & $.8555(.2221)^{* * *}$ \\
\hline Wald chi-squared test of model & $67.78^{* * *}$ & $96.43^{* * *}$ \\
\hline
\end{tabular}

Notes: Key results are robust to defining a dummy variable Sleep Restricted $=1$ for the sleep restricted decision session. In this case, the dummy variable $S R$ is statistically significant $(p<.01)$ and positive with coefficient of 2.0608 , which is about 3 times the magnitude of the significant $(p<.01)$ and positive coefficient on Circadian Mismatched of .6248 in that specification. Results are also robust to the use of objective nightly sleep the week prior to the decision session to measure sleep restriction (rather than Personal SD) 
Figure S2: Self-Report Mood Ratings on $n=80$ subject subset of data.

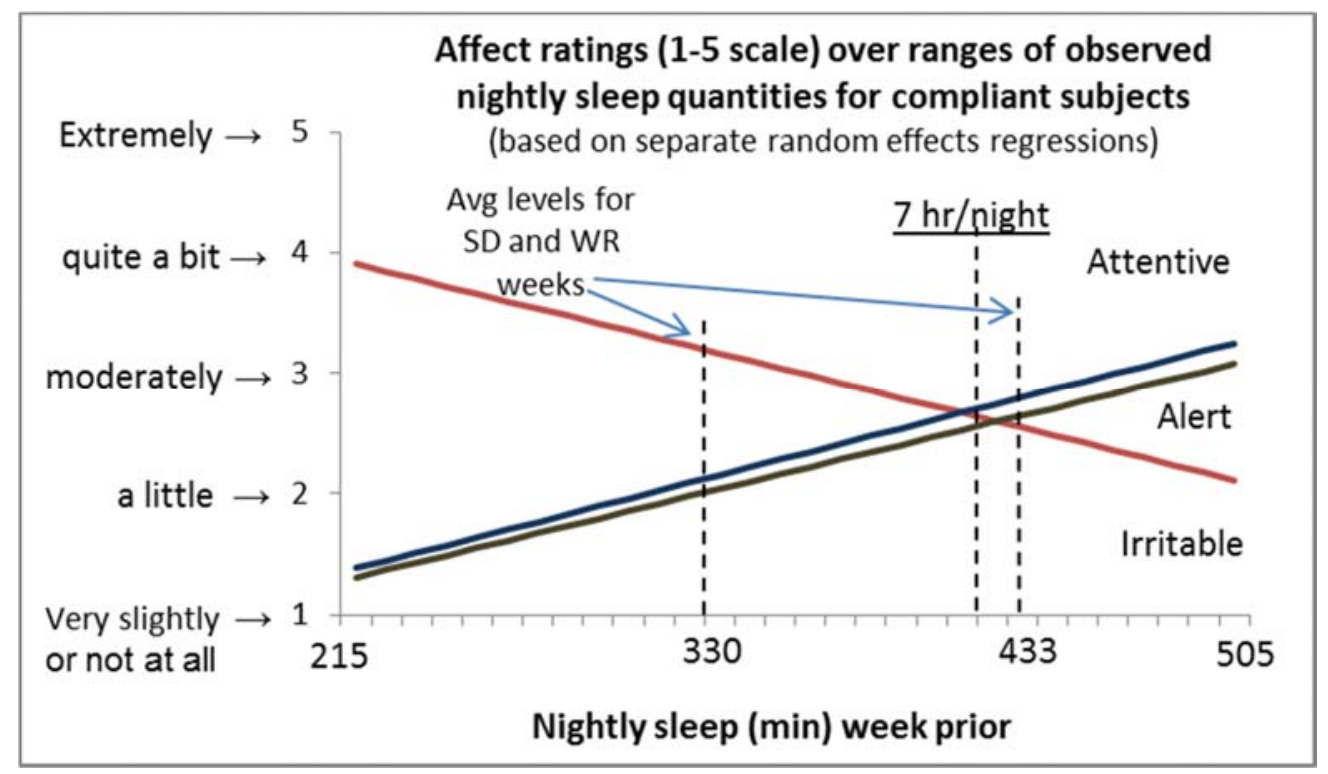

For the subset of subjects administered the PANAS affective scale instrument, the random Effects estimation results document a significant negative impact of reduced sleep the prior week on irritability, attentiveness, and alertness. 


\section{STATISTICAL ANALYSIS}

\section{Full Estimations of Key Outcome Models}

Table S4: Key Outcome Estimations with categorical variables only for experimental manipulation (along with controls for morningness/eveningness preference, session time-of-day, and session number)

\begin{tabular}{|c|c|c|c|c|c|c|}
\hline \multicolumn{7}{|c|}{$\begin{array}{l}\text { Random effects GLS regressions } \\
\text { Standard errors clustered on subject ( } 2 \text { observations per subject) }\end{array}$} \\
\hline Variable & $\begin{array}{l}\text { Ultimatum } \\
\$ \$ \text { Kept }\end{array}$ & $\begin{array}{l}\text { Ultimatum } \\
\text { MAO }\end{array}$ & $\begin{array}{l}\text { Dictator } \\
\$ \$ \text { Kept }\end{array}$ & $\begin{array}{c}\text { Trust } \\
\text { person } \\
\$ \$ \text { kept } \\
\end{array}$ & $\begin{array}{c}\text { Trust } \\
\text { Distribution } \\
\$ \$ \text { kept }\end{array}$ & $\begin{array}{c}\text { Trust- } \\
\text { worthiness^ }\end{array}$ \\
\hline $\mathrm{SR}(=1)$ & $\begin{array}{c}.084 \\
(.088) \\
\end{array}$ & $\begin{array}{c}-.019 \\
(.131) \\
\end{array}$ & $\begin{array}{c}.491 \\
(.199)^{* *}\end{array}$ & $\begin{array}{c}.476 \\
(.248)^{*}\end{array}$ & $\begin{array}{c}.076 \\
(.249)\end{array}$ & $\begin{array}{l}-.017 \\
(.013) \\
\end{array}$ \\
\hline $\mathrm{MM}(=1)$ & $\begin{array}{l}-.077 \\
(.170)\end{array}$ & $\begin{array}{c}.234 \\
(.300)\end{array}$ & $\begin{array}{c}.217 \\
(.333)\end{array}$ & $\begin{array}{c}.119 \\
(.363)\end{array}$ & $\begin{array}{l}-.521 \\
(.396)\end{array}$ & $\begin{array}{l}-.001 \\
(.024)\end{array}$ \\
\hline $\begin{array}{l}\text { Morning Session } \\
\quad(=1)\end{array}$ & $\begin{array}{c}-.079 \\
(.169)\end{array}$ & $\begin{array}{c}.362 \\
(.300)\end{array}$ & $\begin{array}{c}-.284 \\
(.333)\end{array}$ & $\begin{array}{l}-.273 \\
(.363)\end{array}$ & $\begin{array}{l}.288 \\
(.396)\end{array}$ & $\begin{array}{l}.003 \\
(.024)\end{array}$ \\
\hline $\begin{array}{c}\text { MEQ score } \\
\text { (higher=MT) }\end{array}$ & $\begin{array}{l}-.0007 \\
(.015)\end{array}$ & $\begin{array}{l}-.012 \\
(.027)\end{array}$ & $\begin{array}{c}.016 \\
(.030) \\
\end{array}$ & $\begin{array}{c}.053 \\
(.033) \\
\end{array}$ & $\begin{array}{c}.024 \\
(.036) \\
\end{array}$ & $\begin{array}{l}-.001 \\
(.002)\end{array}$ \\
\hline Session \#3 (=1) & $\begin{array}{c}.175 \\
(.088)^{* *}\end{array}$ & $\begin{array}{c}-.590 \\
(.131)^{* * *}\end{array}$ & $\begin{array}{c}.704 \\
(.199)^{* * *}\end{array}$ & $\begin{array}{c}.622 \\
(.248)^{* *}\end{array}$ & $\begin{array}{c}.014 \\
(.249) \\
\end{array}$ & $\begin{array}{c}.037 \\
(.013)^{* * *}\end{array}$ \\
\hline Constant Term & $\begin{array}{c}5.500 \\
(.245)^{* * *}\end{array}$ & $\begin{array}{c}2.044 \\
(.429)^{* * *}\end{array}$ & $\begin{array}{c}6.006 \\
(.488)^{* * *}\end{array}$ & $\begin{array}{c}3.898 \\
(.537)^{* * *}\end{array}$ & $\begin{array}{c}5.182 \\
(.583)^{* * *}\end{array}$ & $\begin{array}{c}.303 \\
(.035)^{* * *}\end{array}$ \\
\hline $\mathrm{N}$ & 234 & 236 & 237 & 230 & 236 & 234 \\
\hline Wald $X^{2}$ & 5.05 & $22.60 * * *$ & $18.40 * * *$ & $11.91 * *$ & 2.84 & $9.36 *$ \\
\hline
\end{tabular}

$*, * *, * * *$ indicate significance at the $.10, .05$, and .01 levels, respectively, for the 2 -tailed test.

'Estimation of the Trustworthiness model using the alternative dependent variable of returned amounts when $50 \%$ or more of pie is trusted shows that the sleep restriction treatment reduced trustworthiness when high levels of trust are at stake $(\beta=-.03, p<.05)$. 
Table S5: Ultimatum Decisions

Random effects GLS regression (for full sample)

Dependent Variable $=$ Portion of $\$ 10$ pie kept (not offered to $2^{\text {nd }}$-mover)

\begin{tabular}{|c|c|c|c|c|}
\multicolumn{4}{c}{} & \multicolumn{2}{c}{$\begin{array}{c}\text { Ultimatum Demands } \\
\text { (n=234 obs) }\end{array}$} & \multicolumn{2}{c|}{$\begin{array}{c}\text { Minimum Acceptable Offer } \\
\text { (n=236 obs) }\end{array}$} \\
\hline & $\mathbf{( 1 )}$ & $\mathbf{( 2 )}$ & $\mathbf{( 3 )}$ & $\mathbf{( 4 )}$ \\
\hline Variable & Coef (st. error) & Coef (st. error) & Coef (st. error) & Coef (st. error) \\
\hline Constant & $5.30(.60)^{* * *}$ & $4.71(.54)^{* * *}$ & $4.71(1.01)^{* * *}$ & $4.70(.94)^{* * *}$ \\
\hline Female (=1) & $.29(.18)$ & $.27(.18)$ & $-.61(.31)^{* *}$ & $-.62(.31)^{* *}$ \\
\hline Age & $.02(.02)$ & $.02(.02)$ & $-.08(.04)^{* *}$ & $-.08(.04)^{* *}$ \\
\hline Depression score & $-.10(.12)$ & $-.11(.12)$ & $.02(.21)$ & $.02(.21)$ \\
\hline Anxiety score & $.02(.04)$ & $.02(.04)$ & $.06(.07)$ & $.06(.07)$ \\
\hline Epworth score & $.01(.03)$ & $.01(.03)$ & $-.03(.04)$ & $-.03(.04)$ \\
\hline Session \#3 & $.18(.09)^{* *}$ & $.18(.09)^{* *}$ & $-.59(.13)^{* * *}$ & $-.59(.13)^{* * *}$ \\
\hline Morning Session (=1) & $-.10(.17)$ & $-.10(.17)$ & $.47(.30)$ & $.47(.30)$ \\
\hline Morningness Score & $-.01(.02)$ & $-.01(.02)$ & $.02(.03)$ & $.02(.03)$ \\
\hline Circadian Mismatched (=1) & $-.02(.17)$ & $.004(.17)$ & $.11(.30)$ & $.11(.30)$ \\
\hline Nightly Sleep week prior (min) & $-.001(.001)$ & --- & $-.00003(.001)$ & --- \\
\hline Personal SD (min/night) & --- & $.0014(.0007)^{* *}$ & --- & $.00001(.001)$ \\
\hline Wald chi-squared test (10) & 9.43 & 12.32 & $31.68^{* * *}$ & $31.75^{* * *}$ \\
\hline
\end{tabular}

$*, * *, * * *$ indicate significance at the $.10, .05$, and .01 levels, respectively, for the 2-tailed test

Table S6: Dictator Decisions

Random effects GLS regression (for full sample)

Dependent Variable $=$ Portion of $\$ 10$ pie kept (not offered to $2^{\text {nd }}$-mover)

\section{Dictator Demands}

( $\mathrm{n}=237$ obs)

\begin{tabular}{|c|c|c|}
\hline & $\mathbf{( 1 )}$ & $\mathbf{( 2 )}$ \\
\hline Variable & Coef (st. error) & Coef (st. error) \\
\hline Constant & $8.61(1.22)^{* * *}$ & $6.04(5.74)^{* * *}$ \\
\hline Female (=1) & $.03(.36)$ & $-.06(.35)$ \\
\hline Age & $.01(.04)$ & $.02(.04)$ \\
\hline Depression score & $.23(.23)$ & $.18(.23)$ \\
\hline Anxiety score & $-.11(.08)$ & $-.10(.08)$ \\
\hline Epworth score & $-.06(.05)$ & $-.06(.05)$ \\
\hline Session \#3 & $.71(.20)^{* * *}$ & $.72(.20)^{* * *}$ \\
\hline Morning Session (=1) & $-.29(.34)$ & $-.31(.33)$ \\
\hline Morningness Score & $.01(.03)$ & $.02(.03)$ \\
\hline Circadian Mismatched (=1) & $.22(.34)$ & $.32(.33)$ \\
\hline Nightly Sleep week prior (min) & $-.004(.002)^{* *}$ & --- \\
\hline Personal SD (min/night) & --- & $.005(.002)^{* * *}$ \\
\hline Wald chi-squared test (10) & $23.02^{* * *}$ & $29.36^{* * *}$ \\
\hline
\end{tabular}

$*, * *, * * *$ indicate significance at the $.10, .05$, and .01 levels, respectively, for the 2 -tailed test 
Table S7: Trust Decisions

Random effects GLS regression (for full sample)

Dependent Variable $=$ Portion of $\$ 10$ pie kept (not trusted to $2^{\text {nd }}$-mover)

Trust person (Social)

( $n=230$ obs)

\begin{tabular}{|c|c|c|c|c|}
\multicolumn{2}{|c}{ (n=230 obs) } & \multicolumn{2}{c|}{$(\mathrm{n}=236$ obs) } \\
\hline & $\mathbf{( 1 )}$ & $\mathbf{( 2 )}$ & $\mathbf{( 3 )}$ & $\mathbf{( 4 )}$ \\
\hline Variable & Coef (st. error) & Coef (st. error) & Coef (st. error) & Coef (st. error) \\
\hline Constant & $6.09(1.39)^{* * *}$ & $3.49(1.18)^{* * *}$ & $5.52(1.48)^{* * *}$ & $4.60(1.28)^{* * *}$ \\
\hline Female (=1) & $.33(.40)$ & $.24(.39)$ & $.47(.43)$ & $.45(.42)$ \\
\hline Age & $.01(.04)$ & $.01(.04)$ & $-.01(.05)$ & $-.01(.05)$ \\
\hline Depression score & $.27(.26)$ & $.23(.26)$ & $.39(.28)$ & $.36(.28)$ \\
\hline Anxiety score & $-.10(.09)$ & $-.09(.09)$ & $-.10(.09)$ & $-.09(.09)$ \\
\hline Epworth score & $-.01(.06)$ & $-.01(.06)$ & $.03(.06)$ & $.03(.06)$ \\
\hline Session \#3 & $.64(.25)^{* * *}$ & $.63(.25)^{* *}$ & $.02(.25)$ & $.04(.25)$ \\
\hline Morning Session (=1) & $-.26(.38)$ & $-.27(.38)$ & $.32(.41)$ & $.31(.40)$ \\
\hline Morningness Score & $.06(.04)$ & $.06(.04)$ & $.02(.04)$ & $.03(.04)$ \\
\hline Circadian Mismatched (=1) & $.13(.37)$ & $.21(.37)$ & $-.52(.40)$ & $-.47(.40)$ \\
\hline Nightly Sleep week prior (min) & $-.005(.002)^{* *}$ & --- & $-.001(.002)$ & --- \\
\hline Personal SD (min/night) & --- & $.004(.002)^{* *}$ & --- & $.003(.002)$ \\
\hline Wald chi-squared test (10) & 15.44 & $16.07^{*}$ & 6.91 & 8.58 \\
\hline
\end{tabular}

$*, * *, * * *$ indicate significance at the $.10, .05$, and .01 levels, respectively, for the 2 -tailed test

Table S8: Trustworthiness Decisions

Random effects GLS regression (for full sample)

Dependent Variable= average \% returned (from strategy choice set)

\begin{tabular}{|c|c|c|c|}
\hline (n=234 obs) & $\begin{array}{c}\text { DV = Avg } \\
\text { Trustworthiness over } \\
\text { all amounts trusted }\end{array}$ & $\begin{array}{c}\text { DV = Avg } \\
\text { Trustworthiness over } \\
\text { all amounts trusted }\end{array}$ & $\begin{array}{c}\text { DV = Avg } \\
\text { Trustworthiness for } \\
\text { amounts } \geq \text { \$5 trusted }\end{array}$ \\
\hline Variable & $\mathbf{( 1 )}$ & $\mathbf{( 2 )}$ & (3) \\
\hline Constant & $.19(.09)^{* *}$ & $.31(.08)^{* * *}$ & $.45(.09)^{* * *}$ \\
\hline Female (=1) & $-.01(.03)$ & $-.003(.03)$ & $-.02(.03)$ \\
\hline Age & $.001(.003)$ & $.0001(.003)$ & $-.001(.003)$ \\
\hline Depression score & $-.02(.02)$ & $-.02(.02)$ & $-.02(.02)$ \\
\hline Anxiety score & $.005(.006)$ & $.005(.006)$ & $.009(.007)$ \\
\hline Epworth score & $.001(.004)$ & $.001(.004)$ & $.001(.004)$ \\
\hline Session \#3 & $-.04(.01)^{* * *}$ & $-.04(.01)^{* * *}$ & $-.04(.01)^{* * *}$ \\
\hline Morning Session (=1) & $.001(.03)$ & $.002(.02)$ & $.01(.03)$ \\
\hline Morningness Score & $-.001(.002)$ & $-.002(.002)$ & $-.003(.003)$ \\
\hline Circadian Mismatched (=1) & $.0004(.02)$ & $-.004(.02)$ & $-.02(.03)$ \\
\hline Nightly Sleep week prior (min) & $.0002(.0001)^{*}$ & --- & --- \\
\hline Personal SD (min/night) & --- & $-.0002(.0001)^{* *}$ & $-.0003(.0001)^{* * *}$ \\
\hline Wald chi-squared test (10) & 12.84 & 15.60 & $18.24^{* *}$ \\
\hline
\end{tabular}

$*, * *, * * *$ indicate significance at the $.10, .05$, and .01 levels, respectively, for the 2-tailed test Model 3 shows that Personal SD more strongly impacts trustworthiness when a strong initial trust signal is received. 
Figure S4: Trustworthiness Distributions (by sleep condition)
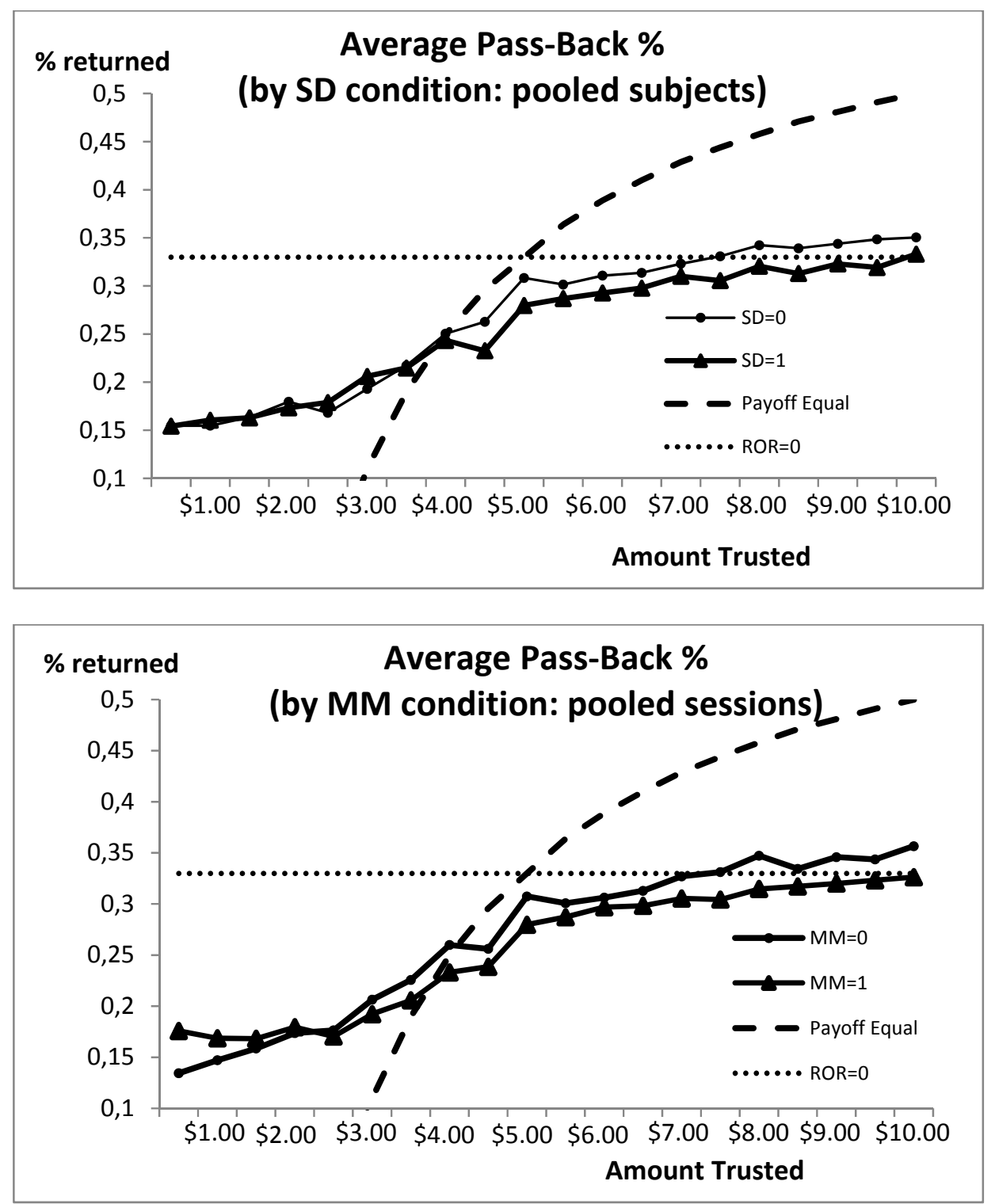

Note: This Fig. 4 does not control for other variables or take into account the repeat-administration nature of the data and is for illustrative purposes only. ROR is the rate-of-return on the first-mover's investment or amount trusted. Because the experimenter triples whatever amount is initially trusted, a one-third trustworthiness level will return back the invested capital to the first-mover. The Payoff Equal amount takes into account that only the first-mover is endowed with the initial $\$ 10$ to trust or not. For example, if all $\$ 10$ is trusted, then the second-mover possess $\$ 30$ (and the first mover possesses zero). The second-mover will have to send back $50 \%$ to guarantee equal payoffs of $\$ 15$ for each.

Table S5-S9 Note: Results in Tables S5-S9 are also robust to the exclusion of extreme sleeper subjects who were personally sleep deprived $>2.5$ hours (SR condition) or $<1 / 2$ hour (WR condition). Standard errors increase slightly, though key results are still statistically significant at $p<.10$ or better. The magnitude of the estimated effects from removing the more extreme sleepers, not surprisingly, is slightly reduced. 
Table S9: Instrumental Variables Estimation to examine sleepiness mediating effects.

\section{Instrumental Variables 2SLS Regression of Behavioral Outcomes \\ (Karolinska sleepiness scores, or KSleepy, is instrumented)}

First Stage Regression: KSleepy instrumented in first stage regression with Session\#3(-), Female(+), Age(+), Anxiety, Depression(-), PersonalSD(+), Epworth Score(+), Morning Session(-), MEQ score, Mismatch(+).

(parentheses highlight significant predictors $(p \leq .10)$ and the direction of their effect on sleepiness in the first stage regression).

Standard errors clustered on subject ( 2 observations per subject)

\begin{tabular}{|c|c|c|c|c|c|c|}
\hline Variable & $\begin{array}{c}\text { Ultimatum } \\
\$ \$ \text { Kept }\end{array}$ & $\begin{array}{c}\text { Ultimatum } \\
\text { MAO }\end{array}$ & $\begin{array}{l}\text { Dictator } \\
\$ \$ \text { Kept }\end{array}$ & $\begin{array}{c}\text { Trust } \\
\text { person } \\
\$ \$ \text { kept } \\
\end{array}$ & $\begin{array}{c}\text { Trust } \\
\text { algorithm } \\
\$ \$ \text { kept }\end{array}$ & $\begin{array}{c}\begin{array}{c}\text { Trust- } \\
\text { worthiness }\end{array} \\
\end{array}$ \\
\hline KSleepy(instr) & $\begin{array}{c}.17 \\
(.08)^{* *}\end{array}$ & $\begin{array}{l}-.04 \\
(13)\end{array}$ & $\begin{array}{c}.46 \\
(.16)^{* * *}\end{array}$ & $\begin{array}{c}.35 \\
(.16)^{* *}\end{array}$ & $\begin{array}{l}.17 \\
(.17)\end{array}$ & $\begin{array}{c}-.02 \\
(.01)^{* *}\end{array}$ \\
\hline Session \#3 & $\begin{array}{c}.25 \\
(.10)^{* *}\end{array}$ & $\begin{array}{c}-.60 \\
(.14)^{* * *}\end{array}$ & $\begin{array}{c}.88 \\
(.22)^{* * *} \\
\end{array}$ & $\begin{array}{c}.79 \\
(.27)^{* * *}\end{array}$ & $\begin{array}{l}.10 \\
(.25)\end{array}$ & $\begin{array}{c}-.04 \\
(.02)^{* * *}\end{array}$ \\
\hline Female & $\begin{array}{c}.13 \\
(.15)\end{array}$ & $\begin{array}{c}-.59 \\
(.31)^{*}\end{array}$ & $\begin{array}{l}-.42 \\
(.37)\end{array}$ & $\begin{array}{l}.002 \\
(.04)\end{array}$ & $\begin{array}{l}.41 \\
(.45)\end{array}$ & $\begin{array}{l}.01 \\
(.03)\end{array}$ \\
\hline age & $\begin{array}{c}.01 \\
(.02)\end{array}$ & $\begin{array}{l}-.06 \\
(.04)\end{array}$ & $\begin{array}{c}.02 \\
(.04)\end{array}$ & $\begin{array}{l}.02 \\
(.04)\end{array}$ & $\begin{array}{l}.005 \\
(.04)\end{array}$ & $\begin{array}{l}.0001 \\
(.002)\end{array}$ \\
\hline $\begin{array}{c}\text { Depression } \\
\text { score }\end{array}$ & $\begin{array}{l}.06 \\
(.09) \\
\end{array}$ & $\begin{array}{l}.002 \\
(.19) \\
\end{array}$ & $\begin{array}{c}.30 \\
(.22) \\
\end{array}$ & $\begin{array}{c}.27 \\
(.27) \\
\end{array}$ & $\begin{array}{c}.34 \\
(.28) \\
\end{array}$ & $\begin{array}{c}.02 \\
(.02) \\
\end{array}$ \\
\hline Anxiety score & $\begin{array}{c}.03 \\
(.03)\end{array}$ & $\begin{array}{c}.05 \\
(.07) \\
\end{array}$ & $\begin{array}{c}-12 \\
(.07) \\
\end{array}$ & $\begin{array}{l}.10 \\
(.07)\end{array}$ & $\begin{array}{c}.09 \\
(.07) \\
\end{array}$ & $\begin{array}{c}.005 \\
(.005) \\
\end{array}$ \\
\hline Constant & $\begin{array}{c}4.09 \\
(.71)^{* * *}\end{array}$ & $\begin{array}{c}4.83 \\
(1.19)^{* * *}\end{array}$ & $\begin{array}{c}4.07 \\
(1.31)^{* * *}\end{array}$ & $\begin{array}{c}2.56 \\
(1.22)^{* *}\end{array}$ & $\begin{array}{c}4.25 \\
(1.27)^{* * *}\end{array}$ & $\begin{array}{c}.38 \\
(.09)^{* * *}\end{array}$ \\
\hline $\mathrm{N}$ & 234 & 236 & 237 & 230 & 236 & 234 \\
\hline Wald $X^{2}$ & 10.42 & $30.97^{* * *}$ & $25.45 * * *$ & 12.19* & 5.89 & 11.91* \\
\hline
\end{tabular}

$*, * *, * * *$ indicate significance at the $.10, .05$, and .01 levels, respectively, for the 2-tailed test.

Ksleepy scores are the average of the pre- and post-decision Karolinska self-report sleepiness ratings for each subject.

The same 2SLS model run using the alternative Trustworthiness variable (i.e., average percentage passed back on all possible first-mover trusted amounts of at least half the pie), shows similar results to the Trustworthiness model above, except that the magnitude of the instrumented KSleepy variable is a bit larger in magnitude (-.025 vs -.019$)$ and estimated a bit more precisely ( $p=.03 \mathrm{vs} p=.038)$. This is consistent with what is reported in the main text that the impact of sleep restriction (via the mediating variable, self-reported sleepiness) to reduce trustworthiness is magnified for those decisions involving a more sizeable and clear signal of trust by the first-mover. 


\section{SI Appendix References}

22. Goldman, S. E., Stone, K. L., Ancoli-Israel, S., Blackwell, T., Ewing, S. K., Boudreau, R., ... Newman, A. B. Poor sleep is associated with poorer physical performance and greater functional limitations in older women. Sleep, 30, 1317-1324 (2007).

23. Horne J. A., \& Östberg, O. A self-assessment questionnaire to determine morningness-eveningness in human circadian rhythms. Int J Chronobiol, 4(2), 97-110 (1976).

24. Chelminski, I., Petros, T.V., Plaud, J.J., \& Ferraro, F. R. Psychometric properties of the reduced Horne and Östberg questionnaire. Personality and Individual Differences, 29, 469-78 (2000).

25. Watson, D., Clark, L. A., \& Tellegen, A. Development and validation of brief measure of positive and negative affect: The PANAS scales. Journal of Personality and Social Psychology, 54(6), 1063 (1988). 